\title{
Evaluation of Job Strain of Family Physicians in COVID-19 Pandemic Period- An Example from Turkey
}

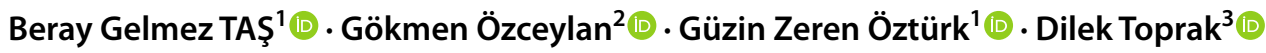

Accepted: 7 November 2020 / Published online: 14 November 2020

(c) Springer Science+Business Media, LLC, part of Springer Nature 2020

\begin{abstract}
The purpose of this study was to evaluate family physicians' job strain during the Covid-19 pandemic and determine the effective factors. The study was carried out between 01 May 2020 and 01 June 2020 by applying an online questionnaire to family physicians who worked in primary care in Istanbul and could be reached by telephone application. The survey created by us included socio-demographic information and the Job Strain Scale Short Form. $P$ value was accepted as 0.05, and SPSS 20 package program was used in statistical analysis. 448 Family Physicians participated in the study. Anxiety levels of the participants increased after the pandemic $(p<0.001)$. Job strain score increased significantly during the pandemic process $(p<0.001)$. The 'Workload' sub-dimension of the job strain score was affected by young age, not having children, thinking that the working hours increased, deterioration of sleep quality and increasing anxiety level. It was determined that there was an increase in the "Control" sub-dimension score of family physicians who thought that they were not provided with adequate protective equipment during the pandemic process and who did not find the use of their own personal protective equipment sufficient. 'Social support' sub-dimension mean score decreased during the pandemic period. It was determined that it significantly increased in married family physicians compared to single ones. In the pandemic process, anxiety, sleep quality deterioration and job strain increased significantly. In family physicians, after the pandemic, workload and control sub-dimension changes increased, while social support sub-dimension decreased.
\end{abstract}

Keywords Family Physicians · COVID-19 · Job strain

\section{Introduction}

COVID-19 began as a viral outbreak in Wuhan, Hubei province in central China. It became effective all over the world in a short time and became the biggest outbreak of

Beray Gelmez TAŞ

drberaygelmez@hotmail.com

Gökmen Özceylan

gokmenozceylan01@hotmail.com

Güzin Zeren Öztürk

guzin_zeren@hotmail.com

Dilek Toprak

dilekt66@yahoo.com

1 Şişli Hamidiye Etfal Research and Training Hospital Family Medicine Depertmant, İstanbul, Turkey

2 Çorlu Reşadiye Family Medicine Center, Çorlu, Tekirdağ, Turkey

3 Head of Family Medicine Depertmant, Namık Kemal Unıversity Medical School, Tekirdağ, Turkey atypical pneumonia since the outbreak of acute respiratory syndrome (SARS) in 2003 [1, 2]. While COVID-19, which started suddenly and spread rapidly, causes infection anxiety in individuals, the measures taken for protection have affected the quality of life of individuals [3]. Since the effects of outbreaks are generally intense, they can affect the mental well-being of the society negatively and cause an increase in stress [4]. In the pandemic period in Turkey, approximately $60 \%$ of the cases were in Istanbul, so it can be thought that it caused the family physicians in Istanbul to be more affected [5].

Job strain is a stress situation that occurs as a result of physical and psychological pressures that the employee feels in the process of fulfilling what is expected by the workplace. Health workers are considered to be at high risk because they are at the forefront of combating the pandemic, and this creates the potential to create stress in them [6]. Family physicians work in various fields especially in emergency and COVID-19 services of hospitals and in family health centers. During the pandemic period, the majority of 
hospitals were transformed into pandemic hospitals, which increased the demand for family physicians working in primary care, and family physicians became the first point of contact for patients. In hospitals, family physicians serve primarily diagnosed or suspicious cases. The increase in risk and workload, of course, can increase the job strain of family physicians.

Stress can also be defined as the reaction of the individual to a situation arising from the strain of physical and mental integrity [7]. In Turkey, like all over the world, stress affects both the health status and the success and performance of the working individuals [8]. For this reason, the assessment of occupational stress loads and the factors affecting them and the application of stress reducing solutions affect both individual and community health.

The purpose of this study was to evaluate family physicians' job strains during the Covid-19 pandemic and determine the effective factors.

\section{Method}

The study was carried out between 01 May 2020-01 June 2020 by applying an online questionnaire to family physicians who worked in primary care in Istanbul and could be reached by telephone application. Voluntary consent form was attached at the beginning of the online questionnaire in order to reduce contact due to the pandemic, and on the condition that it was approved, the questionnaire was included in the study. It was aimed to reach at least 361 physicians from approximately 6000 family physicians working in Istanbul by phone (confidence interval $=5 \%$ ). The survey created by us included socio-demographic information and the Job Strain Scale Short Form.

The first part of the questionnaire includes sociodemographic data (age, gender, working conditions, occupation term etc.). The second part consists of the questions in which the cases of personal protection and measures are evaluated, and the third and the last part includes the questions of "Job Strain Scale Short Form" developed by Theorell et al. and translated to Turkish by Yildırım et al. and later validity and reliability tests performed by Atalay et al. (Cronbach's Alpha 0.891)) [9-11]. This scale consists of 17 questions and three sub-dimensions. "Workload" sub-dimension is composed of 5 questions (1st, 2nd, 3rd, 4th, and 5th), "Control" subdimension consists of 6 questions (6th, 7th, 8th, 9th, 10th and 11th), and "Social Support" sub-dimension is composed of 6 questions (12th, 13th, 14th, 15th, 16th, and 17th). In each of the dimensions examined, the 5-point Likert scale was used. The scoring is between 1: Never and 5: Always. The answer options given to the questions were coded and evaluated between 1 and 5 points. The increase in the total score obtained means that the job strain levels are high.
Individuals were asked to mark separately for both periods to distinguish the situation before and after the pandemic.

Before the research, ethical approval was obtained from University of Health Sciences Turkey, Şişli Hamidiye Etfal Health Training and Research Hospital Ethics Committee (University of Health Sciences Turkey, Şişli Hamidiye Etfal Health Training and Research Hospital İnstitutional Revie w Board) on 22 April 2020 numbered 2725.. Verbal and written informed consent forms were received from all participants in the study.

It was determined that the measurements in the study were not distributed normally. Mann-Whitney U test from non-parametric tests was applied. The parameters used in the study were categorized as categorical and individual. Numerical data were shown as mean and standard deviation, and categorical data as median and percentages. T-tests were used to compare numerical data, and chi-square tests were used to compare categorical data. Wilcoxon test was used to compare pre and post test scores of strain scale, anxiety levels, and sleep quality scores. $P$ value was accepted as 0.05 , and SPSS 20 package program was used in statistical analysis.

\section{Results}

448 Family Physicians participated in the study. The average age of the participants in the study was $39.10 \pm 9.59$ ( $\mathrm{min}$ 24, $\max 65)$.

\section{Evaluation of Information About COVID-19 Pandemic, Contact and Protective Equipment Conditions}

Family physicians participating in the study were asked to indicate their level of knowledge about the COVID-19 outbreak and preventive measures. Evaluation of the level of knowledge of family physicians about COVID-19 pandemic was $33.5 \%(n=150)$ sufficient, $53.6 \%(n=240)$ partially, $12.9 \%(n=58)$ insufficient. In addition, assessment of their level of knowledge about preventive measures was $40.4 \%$ $(n=181)$ sufficient, $45.5 \%(n=204)$ partially, $14.1 \%(n=63)$ insufficient.

The most frequently source used by family physicians participating in the study to get information about COVID19 pandemic and protection methods was academic sites (\% 37,7).

Academic sites (37.7\%) are the most frequently used sources for information about COVID-19 outbreak and prevention methods by the family physicians participating in the research, others were Covid-19 guide of Turkish ministry of health $(\% 35,5)$, social media $(\% 16,3)$, television $(\% 4,7)$, social environment $(\% 4,7)$. 
The rate of contact history of the participants with a COVID-19 (+) individual was $32.8 \%(n=147)$. While $9.8 \%$ $(n=44)$ of the family physicians participating in the study stated that they were provided with sufficient personal protective equipment, $51.1 \%(n=229)$ said they were partially provided and $39.1 \%(n=175)$ stated that sufficient personal protective equipment was not provided at all. When the participants were asked to list the first three personal protective equipment they lacked in order of importance, they stated the lack of disposable overalls in the first place. The three personal protective equipment deficiencies they experienced the most are given in Fig. 1, respectively.

\section{Evaluation of Sleep and Anxiety Status of Family Physicians During the Pandemic Process}

While the rate of family physicians who evaluated sleep quality as very poor before the onset of the pandemic was $1.3 \%(n=6)$, this rate increased to $13.8 \%$ during the pandemic process $(n=62)$. While the rate of those who reported sleep quality as poor before the pandemic was $12.7 \%(n=57)$, this rate increased to $48.2 \%(n=216)$ after the pandemic. While $65.4 \%(n=293)$ of the family physicians participating in the study defined sleep quality as good before the pandemic, this rate decreased to $35.7 \%(n=160)$ after the pandemic. While the rate of those who stated that the quality of sleep before pandemic was very good was $20.5 \%(n=92)$, this rate decreased to $2.2 \%(n=10)$ after the pandemic $(p<0.001)$.

Thinking that personal protective measures were insufficient $(p=0.000)$ and working as a practitioner as a professional title were the most important factors affecting the deterioration of sleep quality $(p=0.004)$. Age, gender, marital status, having a child, the institution of employment, the years spent in the profession, and having contact history with Covid-19 positive cases were not effective in impairing sleep quality $(p>0.05)$.

The family physicians were asked to evaluate their anxiety levels before the pandemic on a scale of 100 . The anxiety levels before the pandemic stated by the participants were an average of 20 out of 100 . By accepting this value as the cut-off value, the level of anxiety after pandemic rose to an average of 70 out of 100 . After the pandemic, there were 429 family physicians $(95.8 \%)$ whose anxiety increased compared to before. While there were $10(2.2 \%)$ people whose anxiety level did not change, there were 9 $(2.0 \%)$ people whose anxiety level decreased. The anxiety levels of the participants increased after the pandemic, which was statistically significant at $p<0.001$.

The most important reason that the participating family physicians thought increased their anxiety was to infect the family members with a rate of $83.7 \%(n=375)$ (Fig. 2).

According to the changes expressed by the family physicians in their anxiety levels, the related factors were evaluated by dividing them into two groups (the same or decreasing anxiety level in the pandemic process, Group I; the increased anxiety level, Group II) (Table 1). Family physicians, whose anxiety level increased during the pandemic process, were found to be related to gender, positive contact history and sufficient knowledge level. Those who had a positive contact history and those with sufficient knowledge were less likely to have anxiety than women, those with no contact history, and partial or insufficient knowledge.
Fig. 1 The distribution of the first three personal equipment that the family physicians could not have access to during the pandemic

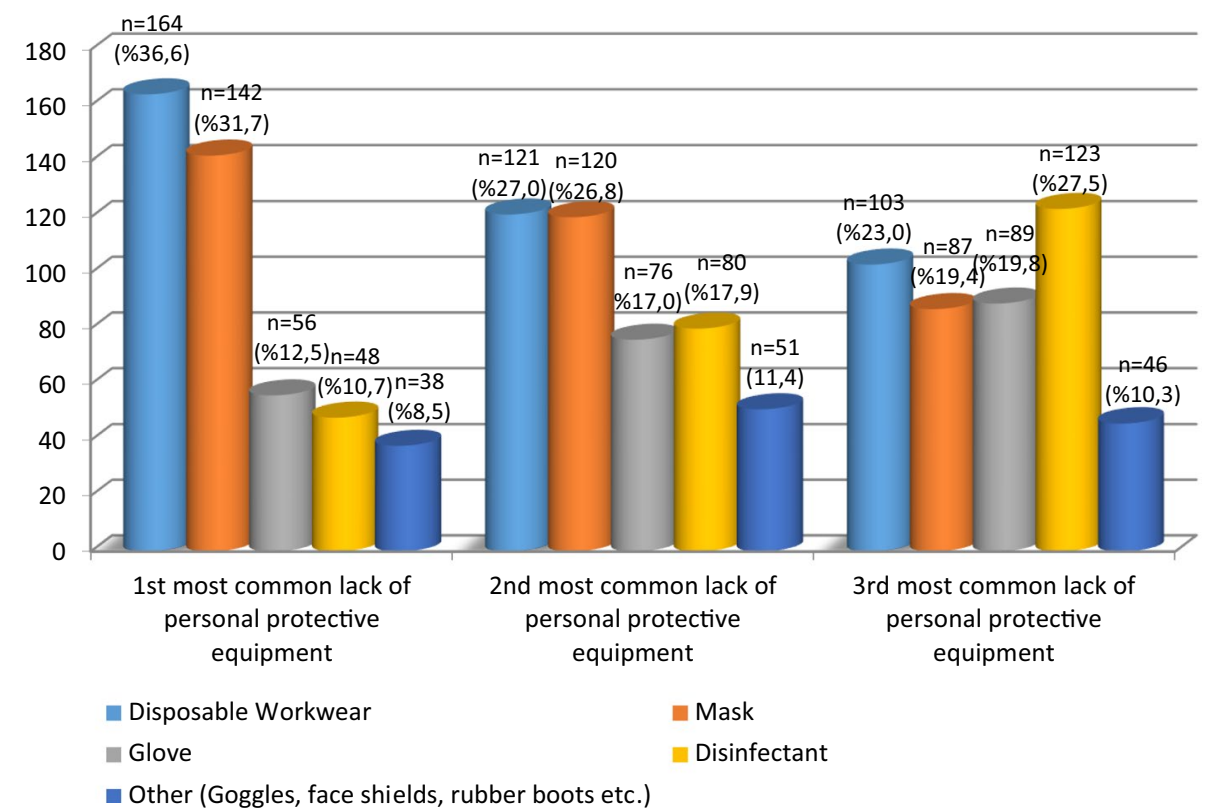


Fig. 2 Distribution of reasons that family physicians stated to increase their anxiety

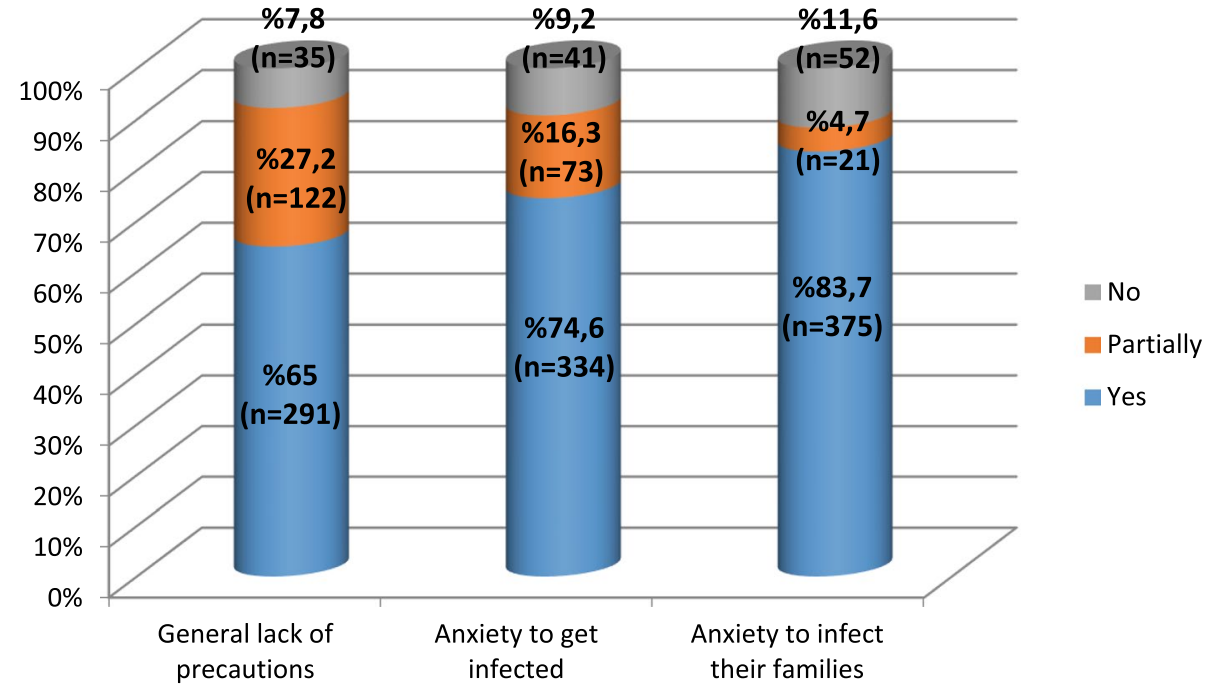

\section{Assessment of Family Physicians' Working Status and Job Strain Score During Pandemic}

$50.7 \%(n=227)$ of the family physicians participating in the study stated that their working hours decreased after the pandemic, $40.8 \%$ said $(n=183)$ it did not change, and $8.5 \%$ $(n=38)$ indicated that their working hours increased. .

The job strain average score of the family physicians participating in the study was $60.1 \pm 6.4(\min 33$, max 77$)$ before the pandemic; after the pandemic, it was $61.6 \pm 6.8$ ( $\min 36, \max 82$ ). The number of family physicians whose mean score of job strain increased in comparison to prepandemic period was 277 (61.8\%). This group was named as Group 1 in the study. The number of family physicians whose job strain score did not change was 52 (11.6\%). The number of family physicians whose job strain score decreased in the pandemic process was 119 (26.6\%). Those whose job strain decreased and did not change were divided into a subgroup as Group 2. It was found that the job strain score increased significantly during the pandemic process $(p<0.001)$.

The factors related to the change in the levels of job strain scores of the family physicians with respect to these two subgroups are given in Table 2. In the analysis of the factors affecting the change according to these subgroup, it was determined that there was no relation between the change and age, gender, marital status, having children, occupational title, institution of employment, time spent in the profession, being in contact with positive individuals during the pandemic process, having sufficient information about COVID-19 disease and the change in working hours during the pandemic.

In the examination of the subgroups of job strain scores, the first subgroup workload sub-dimension average before the pandemic was $3.37 \pm 0.47(\min 1.60$, $\max 4.80)$, while the average after the pandemic was $3.39 \pm 0.52(\min 1.80$, max 4. 80). During the pandemic, the number of family physicians whose workload dimension mean score increased was 187 (41.7\%), while the number of family physicians with decreasing or not changing workload was $261(58.3 \%)$. It was found that workload dimension change before and after pandemic increased significantly $(p=0.000)$. When the factors affecting the increase in the workload dimension were analyzed, they were found to be significantly higher in younger age family physicians (25-29 age group) than other age groups $(p=0.022)$. Family physicians, who indicated that the workload dimension increased, were family physicians who stated that they were provided and used personal protective equipment adequately ( $p=0.001 ; p=0.033$, respectively). The physicians whose workload dimension increased were significantly higher in the family physician group who stated that their working hours increased $(p=0.049)$. Family physicians whose workload dimension increased were the family physicians whose sleep quality deteriorated and their anxiety level increased during the pandemic $(p=0.000$; $\mathrm{p}=0.000$, respectively).

When the control dimension, which is the second subdimension of the job strain scale was examined, the 'Control' sub-dimension of the job strain before the pandemic was $3.39 \pm 0.51(\min 1.67, \max 4.67)$, while this average rose to $3.40 \pm 0.53$ after the pandemic. ( $\min 1.67, \max 5.00)$ This increase was statistically significant $(p=0.000)$. The number of family physicians whose control sub-dimension mean score increased was 131 (29.2\%). This sub-dimension score increase was significantly higher in family physicians who thought that they were not provided with adequate protective equipment during the pandemic process and in family physicians who did not find their own personal protective equipment sufficient ( $p=0.007 ; p=0.022$, respectively). 
Table 1 Evaluation of factors related to the change in anxiety states in the pandemic process

\begin{tabular}{|c|c|c|c|}
\hline & $\begin{array}{l}\text { Group I }(n=19) \\
\mathrm{n}(\%)\end{array}$ & $\begin{array}{l}\text { Group II }(n=429) \\
\mathrm{n}(\%)\end{array}$ & $p$ \\
\hline \multicolumn{4}{|l|}{ Gender } \\
\hline Male & $16(6,3)$ & $238(93,7)$ & \multirow[t]{2}{*}{$\mathbf{0 , 0 1 3}$} \\
\hline Female & $3(1,5)$ & $191(98,5)$ & \\
\hline \multicolumn{4}{|l|}{ Marial Status } \\
\hline Married & $11(3,4)$ & $311(96,6)$ & \multirow[t]{2}{*}{0,166} \\
\hline Single & $8(6,3)$ & $118(93,7)$ & \\
\hline \multicolumn{4}{|l|}{ Number of children } \\
\hline 0 & $9(5,3)$ & $160(94,7)$ & \multirow{4}{*}{0,657} \\
\hline 1 & $3(2,6)$ & $114(97,4)$ & \\
\hline 2 & $5(3,9)$ & $126(96,1)$ & \\
\hline 3 and over & $2(6,1)$ & $33(93,9$ & \\
\hline \multicolumn{4}{|l|}{ Institution } \\
\hline Family Health Center & $16(4,2)$ & $361(95,8)$ & \multirow[b]{2}{*}{0,924} \\
\hline Hospital & $3(4,2)$ & $68(95,8)$ & \\
\hline \multicolumn{4}{|l|}{ Professional Title } \\
\hline General Practitioner & $13(4,2)$ & $298(95,8)$ & \multirow[b]{2}{*}{0,923} \\
\hline Resident/Specialist & $6(4,4)$ & $131(95.6)$ & \\
\hline \multicolumn{4}{|c|}{ Professional Working Years } \\
\hline $0-3$ year/s & $4(5,3)$ & $72(94,7)$ & \multirow{4}{*}{0,933} \\
\hline $3-10$ years & $6(4,8)$ & $118(95,2)$ & \\
\hline $10-30$ years & $7(3,2)$ & $209(96,8)$ & \\
\hline 30 years and over & $2(6,3)$ & $30(93,8)$ & \\
\hline \multicolumn{4}{|c|}{ History of Contact with Covid-19 Positive Person } \\
\hline Yes & $11(57,9)$ & $136(31,7)$ & \multirow[t]{2}{*}{$\mathbf{0 , 0 1 7}$} \\
\hline No & $8(42,1)$ & $293(68,3)$ & \\
\hline \multicolumn{4}{|c|}{ Sufficient Knowledge of Covid-19 } \\
\hline Yes & $12(63,2)$ & $138(32,2)$ & \multirow{3}{*}{$\mathbf{0 , 0 1 8}$} \\
\hline No & $2(10,5)$ & $56(13,1)$ & \\
\hline Partially & $5(26,3)$ & $235(54,8)$ & \\
\hline \multicolumn{4}{|c|}{ Adequate Personal Protective Equipment } \\
\hline Yes & $2(10,5)$ & $42(9,8)$ & \multirow{3}{*}{0,713} \\
\hline Partially & $9(47,2)$ & $166(38,7)$ & \\
\hline No & $8(42,1)$ & $221(51,5)$ & \\
\hline \multicolumn{4}{|l|}{ Change in Working Hours } \\
\hline Increased & $4(21,1)$ & $34(7,9)$ & \multirow{3}{*}{0,131} \\
\hline Decreased & $8(42,1)$ & $219(51,0)$ & \\
\hline No change & $7(36,8)$ & $176(41,0)$ & \\
\hline
\end{tabular}

Bold values indicate statistical significance $(p<0.05)$
The third subgroup of the job strain scale, the 'Social support' dimension was $3.81 \pm 0.56(\min 1.5$, $\max 5.0)$ before the pandemic, while it regressed to $3.59 \pm 0.63$ ( $\mathrm{min}$ 1.5, max 5.0) after the pandemic. The decrease in the social support sub-dimension of the job strain scale was statistically significant $(p=0.000)$. The number of family physicians whose social support sub-dimension scores increased was only 38 (8.5\%). Those whose mean score of the social support sub-dimension of the scale increased were mostly married $(p=0.002)$.
In the pandemic process, there was no significant relationship between anxiety levels and job strain burden of the participants $(p=0.962)$, while there was a significant positive relationship between impaired sleep quality and increased job strain burden $(p<0.001)$. No significant relation was found between impaired sleep quality and anxiety level increase in the pandemic process $(p=0.403)$. 
Table 2 Evaluation of the factors associated with the change of job strain scores in the pandemic process

\begin{tabular}{|c|c|c|c|}
\hline & Grup I $(n=171) \mathrm{n}(\%)$ & $\begin{array}{l}\text { Grup II } \\
(n=277) \mathrm{n}(\%)\end{array}$ & $\mathrm{p}$ \\
\hline \multicolumn{4}{|l|}{ Gender } \\
\hline Male & $180(70,9)$ & $74(29,1)$ & \multirow[t]{2}{*}{0,199} \\
\hline Female & $148(76,3)$ & $46(23,7)$ & \\
\hline \multicolumn{4}{|l|}{ Marial Status } \\
\hline Married & $239(74,2)$ & $83(25,8)$ & \multirow[t]{2}{*}{0,441} \\
\hline Single & $89(70,9)$ & $37(29,7)$ & \\
\hline \multicolumn{4}{|l|}{ Number of children } \\
\hline 0 & $115(68,0)$ & $54(32,0)$ & \multirow{4}{*}{0,097} \\
\hline 1 & $95(81,2)$ & $22(18,3)$ & \\
\hline 2 & $95(73,6)$ & $34(26,4)$ & \\
\hline 3 and over & $23(69,0)$ & $10(30,3)$ & \\
\hline \multicolumn{4}{|l|}{ Institution } \\
\hline Family Health Center & $274(72,7)$ & $103(27,3)$ & \\
\hline Hospital & $103(76,1)$ & $17(23,9)$ & 0,556 \\
\hline \multicolumn{4}{|l|}{ Professional Title } \\
\hline General Practitioner & $221(71,1)$ & $90(28,9)$ & \multirow[t]{2}{*}{0,121} \\
\hline Resident/Specialist & $107(78,1)$ & $30(21,9)$ & \\
\hline \multicolumn{4}{|c|}{ Knowledge Level about Covid-19 } \\
\hline Sufficient & $103(68,7)$ & $47(31,3)$ & \multirow{3}{*}{0,199} \\
\hline Partially & $184(76,7)$ & $56(23,3)$ & \\
\hline Insufficient & $41(70,7)$ & $17(29,3)$ & \\
\hline \multicolumn{4}{|c|}{ History of Contact with Covid-19 Positive Person } \\
\hline Yes & $114(77,6)$ & $214(71,1)$ & \multirow[t]{2}{*}{0,147} \\
\hline No & $33(22,4)$ & $87(28,9)$ & \\
\hline \multicolumn{4}{|c|}{ Adequate Personal Protective Equipment } \\
\hline Yes & $37(84,1)$ & $7(15,9)$ & \multirow{3}{*}{0,128} \\
\hline Partially & $167(72,9)$ & $62(27,1)$ & \\
\hline No & $124(70,9)$ & $51(29,1)$ & \\
\hline \multicolumn{4}{|c|}{ Change in Working Hours } \\
\hline Increased & $24(63,2)$ & $14(11,7)$ & \multirow{3}{*}{0,342} \\
\hline Decreased & $168(74,0)$ & $59(26,0)$ & \\
\hline No change & $136(74,3)$ & $47(25,7)$ & \\
\hline
\end{tabular}

\section{Discussion}

COVID-19 quickly emerged as a global pandemic that created unexpected stress on all aspects of society. Easy transmission, lack of population immunity, delayed test results, lack of personal protective equipment (PPE), difficulties in implementing community-based measures to limit contact have created an unprecedented challenge on our health, political, economic and social welfare systems [12].

Following the developments in China before the first case was seen in Turkey, the scientific committee was established on 1 October 2020 by the Ministry of Health, and the first guidelines were published online on 14 January 2020 and many scientific programs were organized as online or inservice training [5]. Therefore, in our study, it was determined that the number of people who thought that their knowledge regarding COVID-19 (12.9\%) and PPE (14.1\%) was insufficient was low. As a matter of fact, in our study, academic websites (37.7\%) were the most frequently used sources $(37.7 \%)$ by family physicians to get information about COVID-19 pandemic and protection methods, which was followed by official announcements.

While $39.1 \%(n=175)$ of the family physicians participating in the study stated that they were not provided with sufficient personal protective equipment, the most missing items were disposable overalls, masks and gloves. We think that this situation is caused by the problems in the supply of products as a result of unnecessary intense demand for these materials due to the concerns and fears that occurred in the society at the beginning of the pandemic. In a publication, it was determined that since the rules of use of masks and disinfectants in many countries (such as how many hours the 
mask should be changed, how often it should be changed) were not clear, people bought more than necessary and caused the resources to run out in the market [13].

In our country, the state's intervention in the sale and production of these materials has eliminated these troubles experienced at the beginning of the pandemic [14]. Fixed amount of stocking and follow-up of PPE materials in health institutions independent from the outbreak can be a viable measure for these situations [15]. Stockpiling, which caused resource depletion at the beginning of the pandemic, may be one of the reasons that increased the anxiety of health workers in this period $[16,17]$.

Although each outbreak has important differences due to its geographical location, pathogenic characteristics, transmission route, contagion, mortality and treatment methods, the effects of outbreak on health personnel's psychological health are observed at different levels [18].

There was a statistically significant increase in both sleep quality and anxiety levels of the family physicians who participated in our study compared to the period before pandemic. Sleep is a requirement for the human body. There are many studies on sleep and its psychological effects. Psychological problems can impair sleep quality, and sleep disorders can trigger psychological problems $[19,20]$. This is because when sleep quality is impaired, normal working efficiency decreases as well as attention/memory and mood disorders [21]. In our study, those who thought that the sleep quality was bad increased to $48.2 \%(n=216)$ after the pandemic. In a study conducted in India, the rate of those who had difficulty sleeping during the pandemic process was $28 \%$ [4].

In our study, factors affecting the deterioration of sleep quality were found to be significantly correlated with thinking that personal protective measures are insufficient and being a general practitioner. PPE deficiencies that intensify the fear of corona virus exposure in the workplace can contribute to psychological distress or other diseases and in this case may cause sleep disorder [17].

The poor sleep quality of physicians working as general practitioners may stem from the fact that the general practitioner group consists of newly graduated physicians from the university and that they experience anxiety due to low experience compared to experienced physicians.

Anxiety is a common response to stressful situations [4]. In our study, anxiety level of $95.8 \%$ of family physicians increased after the pandemic compared to the period before. This increase may affect mental health negatively. Similarly, additional changes such as isolation, social distance, quarantine, travel restrictions, and rumors that are constantly spreading on social media are likely to negatively affect mental health [22]. Studies in the literature show that disasters experienced such as terrorism and outbreaks affect the psychological status of health workers [23-25]. In the early stage of the SARS outbreak, a number of psychiatric morbidities were reported, such as permanent depression, anxiety, panic attacks, psychomotor excitement, psychotic symptoms, delirium, and even suicide [26].

Healthcare professionals are vulnerable to both high risk of infection and mental health problems. Approximately 8 thousand healthcare workers have been infected in our country; about 100 of them were family physicians [27]. Health professionals not only experience anxiety because of their own life, but also they may experience anxiety due to the risk of transmitting the disease to their families, friends or colleagues [16]. In our study, family physicians stated that anxiety of infecting the family members increased their anxiety levels with a maximum rate of $83.7 \%(n=375)$. Intermittent screening of health personnel may be an option to prevent this situation.

In evaluating the factors affecting anxiety levels, it was seen that female gender was one of the influencing factors. Similar to other studies, in our study, it was observed that women had a higher risk of anxiety level and associated negative psychiatric outcomes [28, 29]. This may be because women think that they will infect individuals with whom they are in close contact due to their roles at home (cooking, childcare) outside of work. Lack of information was one of the factors that significantly increased anxiety in our study. Again, we believe that anxiety increase being less in those with a history of contact with COVID-19 positive patients can be because of the increase in knowledge of the subject in individuals.

In our study, in accordance with the literature, the job strain score increased significantly compared to the period before the pandemic [30]. When we examined the subdimensions, it was determined that before and after the pandemic, workload sub-dimension and control sub-dimension changes increased significantly, but social support subdimension decreased [31]. When the factors related to social support were evaluated, the social support score of married individuals being significantly higher than single individuals could be because of the fact that married individuals have family life which supports them socially.

Increasing social support will decrease the job strain score, even though there is little possibility of any planning and regulation for workload and control in this acute period. For this reason, it is an important option to evaluate the psychological situation and provide the necessary support to healthcare professionals online during and after the outbreak [32, 33]. Again, recognition and appreciation of healthcare professionals by hospital management, government and society may have a positive effect on stress experienced by healthcare professionals during outbreaks [34].

In fact, there is evidence that COVID-19 may be an independent risk factor for stress in the health sector [35]. However, it has been shown that medical personnel are not 
only under stress during the outbreak, but can also suffer psychologically long after the first outbreak ends [34].

In our study, while there was no significant relationship found between anxiety level increases and job strain score of the participants in the pandemic process, a significant positive relation was found between impaired sleep quality and increase in job strain score. In another study conducted on healthcare workers, it was found that the gradual increase in the severity of sleep problems increased the degree of job strain by causing difficulties in maintaining a good working status and focusing attention [36]. In another study conducted on health professionals, it was shown that burnout related to job strain may be related to mental health such as depression, anxiety, sleep problems [37]. The effects of emotions such as anxiety, stress and self-efficacy on sleep quality have also been shown in previous studies [38]. Protecting the mental health of healthcare professionals is important for the control of the outbreak and their long-term health [39]. Otherwise, it will negatively affect the work and services of the personnel who have psychological and sociological problems and this will make the control of the outbreak difficult.

\section{Conclusion}

In our study, in the pandemic process, anxiety, sleep quality deterioration and job strain increased significantly. When the sub-dimensions of job strain were examined, the workload dimension before and after the pandemic and the control sub-dimension change increased significantly, while the social support sub-dimension decreased significantly.

It was determined that family physicians' anxiety level increased with positive contact history, low level of knowledge about COVID-19 and being a female, while deterioration of sleep quality increased with the thought that personal protective measures were insufficient.

We think that it will be beneficial for the healthcare workers, whose workload has increased during the pandemic, to be supported both socially and psychologically, to be informed about prevention and protective measures and to be tested intermittently in terms of contamination.

Otherwise, it will negatively affect the work and services of the personnel who have psychological and sociological problems and this will make the control of the outbreak difficult.

\section{Compliance with ethical standards}

Conflict of interest The authors declare that they have no Conflict of interest.

\section{References}

1. Holshue, M. L., DeBolt, C., Lindquist, S., et al. (2020). First case of 2019 novel coronavirus in the United States. The New England Journal of Medicine, 382(10), 929-936. https://doi.org/10.1056/ NEJMoa2001191.

2. Hawryluck, L., Gold, W. L., Robinson, S., Pogorski, S., Galea, S., \& Styra, R. (2004). SARS control and psychological effects of quarantine, Toronto, Canada. Emerging Infectious Diseases, 10(7), 1206-1212. https://doi.org/10.3201/eid1007.030703.

3. Zhang, Y., \& Ma, Z. F. (2020). Impact of the COVID-19 pandemic on mental health and quality of life among local residents in Liaoning Province, China: A cross-sectional study. International Journal of Environment Research Public Health, 17(7), 2381. https://doi.org/10.3390/ijerph17072381.

4. Roy, D., Tripathy, S., Kar, S. K., Sharma, N., Verma, S. K., \& Kaushal, V. (2020). Study of knowledge, attitude, anxiety\&perceived mental health care need in Indian population during COVID-19 pandemic. Asian Journal of Psychiatry, 8(51), 102083. https://doi.org/10.1016/j.ajp.2020.102083 Epubahead of print. PMID: 32283510; PMCID: PMC7139237.

5. https://www.sozcu.com.tr/2020/gundem/10-haziran-corona-virus unde-son-durum-istanbul-ankara-izmirde-vaka-sayisi-artti-mi5867511/. Accessed: 25 June 2020.

6. The Republıc Of Turkey Ministry Of Health Directorate General Of Publıc Health. (2020). Covid-19 (Sars-Cov-2 Infection) (Study Of Scientific Board) https://covid19.saglik.gov.tr/. Accessed: 25 June 2020

7. Baltaş, A., \& ve Baltaş, Z. (1996). Stress and coping strategies. İstanbul: Remzi Books.

8. Erol, T., Zeynep, Ç. Y., \& Selçuk, G. (2019). A research on the ways of coping with stress and perceived stress levels of employees in different professions. Ordu University Journal of Social Science Research, 9(1), 79-89.

9. Theorell T, Perski A, Akerstedt T et all. (1988). Changes in job strain in relation to changes in physiological state. Sc and Journal of Work Environment Health, 14: 189-196.

10. Yunus, Y., Yalçın, T., \& Hanifi, Ü. (2011). Adaptation of job strain questionnaire- short version (validity and reliability study). Selçuk University Journal Of Physical Educatıon And Sport Scıence, 13(1), 103-108

11. Atalay, A., Yücel, A., \& Korkmaz, M. (2015). Determınatıon of Organızational stress levels of the staff Workıng in Provincial Directorates of youth Services and sports. The Journal of Physical Education And Sport Sciences, 13(1), 17-28.

12. Centers for Disease Control and Prevention. How coronavirusspreads. (2020) https://www.cdc.gov/coronavirus/2019-ncov/ prepare/transmission.html. Accessed: 25 June 2020.

13. Feng, S., Shen, C., Xia, N., Song, W., Fan, M., \& Cowling, B. J. (2020). Rational use of face masks in the COVID-19 pandemic. The Lancet Respiratory Medicine, 8(5), 434-436. https://doi. org/10.1016/S2213-2600(20)30134-X.

14. https://www.titck.gov.tr/duyuru/ihracatinda-ve-ithalatindaihraci-yasak-ve-on-izne-bagli-mallara-iliskin-teblig-ihracat-9631-uyarinca-on-izne-tabi-urunler-hakkinda-2020-10-sayili-duyuru-02052020193534. Accessed: 25 June 2020.

15. Mason DJ, Friese CR. (2020). Protecting health care workers against COVID-19 and being prepared for future pandemics. JAMA Health Forum https://jamanetwork.com/channels/healt h-forum/fullarticle/2763478. Accessed: 05 July 2020.

16. Xiang, Y.-T. (2020). Timely mental health care for the 2019 novel coronavirus outbreak is urgently needed. Lancet Psychiatry, 7 , 228-229.

17. Jin, Y. H., Huang, Q., Wang, Y. Y., et al. (2020). Perceived infection transmission routes, infection control practices, psychosocial 
changes, and management of COVID-19 infected healthcare workers in a tertiary acute care hospital in Wuhan: A cross-sectional survey. Military Medical Research, 7(1), 24. Published 2020 May 11. https://doi.org/10.1186/s40779-020-00254-8.

18. Lin, C. Y., Peng, Y. C., Wu, Y. H., et al. (2007). The psychological effect of severe acute respiratory syndrome on emergency department staff. Emergency Medicine Journal, 24(1), 12-17.

19. Baglioni, C., Nanovska, S., Regen, W., et al. (2016). Sleep and mental disorders: A meta-analysis of polysomnographic research. Psychological Bulletin, 142(9), 969-990. https://doi.org/10.1037/ bul0000053.

20. Colten, H. R, Altevogt, B. M., (2006). Institute of Medicine (US) Committee on Sleep Medicine and Research (Eds.). Sleep Disorders and Sleep Deprivation: An Unmet Public Health Problem. National Academies Press (US).

21. Vanttola, P., Härmä, M., Viitasalo, K., et al. (2019). Sleep and alertness in shift work disorder: Findings of a field study. International Archives of Occupational and Environmental Health, 92(4), 523-533. https://doi.org/10.1007/s00420-018-1386-4.

22. Banerjee, D. (2020). The COVID-19 outbreak: Crucial role the psychiatrists can play. Asian Journal of Psychiatry, 50, 102014. https://doi.org/10.1016/j.ajp.2020.102014.

23. Marshall, R. D., Bryant, R. A., Amsel, L., Suh, E. J., Cook, J. M., $\&$ Neria, Y. (2007). The psychology of ongoing threat: Relative risk appraisal, the September 11 attacks, and terrorism-related fears. The American Psychologist, 62(4), 304-316. https://doi. org/10.1037/0003-066X.62.4.304.

24. Marshall, R. D., Galea, S., \& Kilpatrick, D. (2002). Psychiatric consequences of September 11. JAMA, 288(21), 2683-2684; author reply 2684-5. https://doi.org/10.1001/jama.288.21.2683jlt1204-1-3.

25. Peeri, N. C., Shrestha, N., Rahman, M. S., et al. (2020). The SARS, MERS and novel coronavirus (COVID-19) epidemics, the newest and biggest global health threats: what lessons have we learned? International journal of epidemiology, dyaa033. Advance online publication. https://doi.org/10.1093/ije/dyaa033.

26. Maunder, R., Hunter, J., Vincent, L., et al. (2003). The immediate psychological and occupational impact of the 2003 SARS outbreak in a teaching hospital. CMAJ : Canadian Medical Association Journal = Journal de l'Association medicale canadienne, 168(10), 1245-1251.

27. https://www.medimagazin.com.tr/guncel/genel/tr-saglikbakani-fahrettin-koca-enfekte-olan-7428-saglik-calisanimizvar-11-681-88528.html. Accessed: 29 June 2020.

28. Elbay, R. Y., Kurtulmuş, A., Arpacioğlu, S., \& Karadere, E. (2020). Depression, anxiety, stress levels of physicians and associated factors in Covid-19 pandemics. Psychiatry Research, 290, 113130. Advance online publication. https://doi.org/10.1016/j. psychres.2020.113130.

29. Lai, J., Ma, S., Wang, Y., Cai, Z., Hu, J., Wei, N., et al. (2020). Factors associated with mental health outcomes among health care workers exposed to coronavirus disease 2019. JAMA Network Open, 3(3), e203976. https://doi.org/10.1001/jamanetworkopen .2020.3976.

30. Koh, D., Lim, M. K., Chia, S. E., et al. (2005). Risk perception and impact of severe acute respiratory syndrome (SARS) on work and personal lives of healthcare workers in Singapore: What can we learn? Medical Care, 43(7), 676-682. https://doi.org/10.1097/01. mlr.0000167181.36730.cc.

31. Inter-Agency Standing Committee. Briefingnote on addressing mental health and psychosocialaspects of COVID-19 OutbreakVersion1.1.2020.

32. Lai, T., Tang, E., Chau, S., Fung, K., \& Li, K. (2020). Stepping up infection control measures in ophthalmology during the novel coronavirus outbreak: An experience from Hong Kong. Graefe's archive for clinical and experimental ophthalmology $=$ Albrecht von Graefes Archiv fur klinische und experimentelle Ophthalmologie, 258(5), 1049-1055. https://doi.org/10.1007/s0041 7-020-04641-8.

33. Cai, H., Tu, B., Ma, J., Chen, L., Fu, L., Jiang, Y., \& Zhuang, Q. (2020). Psychological impact and coping strategies of frontline medical staff in Hunan between January and march 2020 during the outbreak of coronavirus disease 2019 (COVID-19) in Hubei, China. Medical Science Monitor : International Medical Journal of Experimental and Clinical Research, 26, e924171. https://doi. org/10.12659/MSM.924171.

34. Khalid, I., Khalid, T. J., Qabajah, M. R., Barnard, A. G., \& Qushmaq, I. A. (2016). Healthcare workers emotions, perceived stressors and coping strategies during a MERS-CoV outbreak. Clinical Medicine \& Research, 14(1), 7-14. https://doi.org/10.3121/ cmr.2016.1303.

35. Spoorthy, M. S., Pratapa, S. K., \& Mahant, S. (2020). Mental health problems faced by healthcare workers due to the COVID-19 pandemic-a review. Asian Journal of Psychiatry, 51, 102119. Advance online publication. https://doi.org/10.1016/j. ajp.2020.102119.

36. Duan, X., Wu, Q., Zhu, X., \& Shi, Y. (2017). Improving sleep quality relieves occupational stress in nurses of cardiac surgical intensive care unit. Biomedical Research-tokyo, 28, 3934-3940.

37. Song, K., Choi, W., Jee, H., et al. (2017). Correlation of occupational stress with depression, anxiety, andsleep in Koreandentists: Cross-sectional study. BMC Psychiatry, 17, 398. https://doi. org/10.1186/s12888-017-1568-8.

38. Chen, X. F., Zhang, Y., Xu, X. L., et al. (2019). Mediating roles of anxiety, self-efficacy, and sleep quality on the relationship between patient-reported physician empathy and inflammatory markers in ulcerative colitis patients. Medical Science Monitor : International Medical Journal of Experimental and Clinical Research, 25, 7889-7897. https://doi.org/10.12659/MSM.917552.

39. Kang, L., Li, Y., Hu, S., et al. (2020). The mental health of medical workers in Wuhan, China dealing with the 2019 novel coronavirus. The lancet. Psychiatry, 7(3), e14. https://doi.org/10.1016/ S2215-0366(20)30047-X.

Publisher's Note Springer Nature remains neutral with regard to jurisdictional claims in published maps and institutional affiliations. 